\title{
Growth Performance of Oilseeds Among Leading States in India
}

\author{
Prasanna Kolar", P.K. Awasthi and Ankita Sahu
}

Department of Agricultural Economics \& Farm Management, College of Agriculture, J.N.K.V.V., Jabalpur, Madhya Pradesh, India *Corresponding author: hiprasannakolar@gmail.com (ORCID ID: 0000-0001-9840-1694)

Received: $17-01-2020$

Revised: $26-04-2020$

Accepted: 23-05-2020

\begin{abstract}
The present study was conducted to estimate the growth \& instability of major edible oilseeds production across major states in India. The time series secondary data on area, production and productivity of soybean, rapeseed, mustard and groundnut were collected for all the major states from the period 1995-96 to 2017-18. Statistical tools like compound growth rate for calculating annual growth rate and CuddyDella Valle Index for instability index were used. Results showed that the area and production of soybean in Madhya Pradesh and Maharashtra increased at a highly significant rate annually. Instability of area in both these states was found low. Production and productivity of rapeseed and mustard in Haryana, Rajasthan, Madhya Pradesh were found to be increased at highly significant annual growth rate but the area in Uttar Pradesh was declined at a highly significant rate per annum (-2.93\%). Instability of area in Haryana and Uttar Pradesh was low and production instability was moderate in all four states whereas except Haryana, all three states showed low instability in productivity. In groundnut Andhra Pradesh, Tamil Nadu, Maharashtra and Karnataka showed a highly significant decline in the annual growth rate of area and production. Except for Rajasthan, all other five states showed low instability in the area under groundnut during the study period. Therefore, the study recommends adoption of site-specific scientific package of practices of the crop to avoid the prevailed instability.
\end{abstract}

\section{Highlights}

( Area and production of soybean in Madhya Pradesh \& Maharashtra increased at highly significant rate ( Productivity of rapeseed mustard in all the major states increased at highly significant rate

Keywords: Compound growth rate, instability, Cuddy-Della Valle Index, significant, production, area, productivity

India is the largest producer of oilseeds in the world and oilseed sector occupies an important position in the agricultural economy of the country. India produces a variety of crops belonging to cereals, pulses, oilseeds, fruits and vegetables, condiments, sugar, fibres, narcotics etc. Oilseed crops are the most important commercial crops of India (Soni Kumari, 2012). In terms of acreage, production and economic value, these crops are second after food grains (Narayan, 2016). India is blessed with varied agro-ecological environments ideally suited for growing a variety of oilseeds which include groundnut, rapeseed and mustard, sunflower, soybean, sesamum, safflower, castor, linseed and Niger seed, two perennial oilseeds (coconut and palm oil). India occupies the place of pride as the world's largest producer of groundnuts, sesamum, linseed and castor seeds (Reddy and Immanuelraj, 2017). In the world, India stands at 4th position in soybean area with share of 8.6 per cent to the total

How to cite this article: Kolar, P., Awasthi, P.K. and Sahu, A. (2020). Growth performance of oilseeds among leading states in India. Economic Affairs, 65(2): 219-224.

Source of Support: None; Conflict of Interest: None 
area and in production it occupies $6^{\text {th }}$ position with 3.8 per cent share. In groundnut area, India stands at $1^{\text {st }}$ position in the world with share of 14.9 per cent where as in production it occupies $3^{\text {rd }}$ position with share of 10.5 per cent. In rapeseed \& mustard area India stands at $2^{\text {nd }}$ position with 15.2 per cent share whereas in production it occupies $4^{\text {th }}$ position with share of 9.5 per cent (FAOSTAT, 2018). In India total area of oilseeds was accounted for 24507.90 th.ha whereas production was 31459.26 th.t with yield of $1283.63 \mathrm{~kg} / \mathrm{ha}$. Highest share (27.10 per cent) in area was contributed by Madhya Pradesh state followed by Maharashtra with 16.87 per cent and in production highest share was contributed by Madhya Pradesh with 22.09 per cent followed by Rajasthan with 19.43 per cent. Out of 9 oilseeds, 7 are edible (Soybean, Rapeseed \& Mustard, Groundnut, Sesamum, Sunflower, Safflower, Niger seed) and 2 are non-edible (Castor seed \& Linseed). Out of these 7 edible oilseeds only Soybean (36.79), Groundnut (31.13) and Rapeseed \& Mustard (28.37) contributes to 96.29 per cent of production share in India.

In soybean, Madhya Pradesh and Maharashtra states are contributing most to the production compared to other states i.e.; 48.67 and 34.8 per cent, respectively. In rapeseed \& mustard, Rajasthan and Haryana states are the top 2 states which are contributing maximum to the production i.e., 42.01 and 13.14 per cent, respectively. Where as in Groundnut, Gujarat and Rajasthan are the top 2 states with maximum contribution to the production in India with 42.6 and 13.6 per cent, respectively (DACNET, 2017-18).

Hence there is a need to fill this gap between production and consumption of oilseeds due to the increased demand. Therefore, this study on major edible oilseeds becomes important for the policy makers and planners to emphasize on these crops to fulfil the per capita need through increased production via latest technologies and high yielding varieties and also thereby cutting on imports to reduce import bill of the country. The present paper was undertaken with the objective to estimate the growth \& instability of major edible oilseeds production across leading states in India.

\section{MATERIALS AND METHODS}

\section{Study area and crops}

The area of study comprises of all those states which covered $>80 \%$ of major edible oilseeds production in India. Out of 7 edible oilseeds, major 3 edible oilseeds have been selected as they shared $>80 \%$ of the production in India according to 2016-17 data. Bulk line method was used for selection of these crops and states.

\begin{tabular}{ll}
\hline Crops & States \\
\hline Soybean & Madhya Pradesh, Maharashtra \\
& Rajasthan, Andhra Pradesh, \\
Troundnut & Tamil Nadu, Maharashtra, \\
& Karnataka, Gujarat \\
Rapeseed \& Mustard & $\begin{array}{l}\text { Haryana, Rajasthan, Madhya } \\
\text { Pradesh, Uttar Pradesh }\end{array}$ \\
\hline
\end{tabular}

\section{Period and source of data}

The present study is based on secondary data and the required time series data were collected from Directorate of Economics and Statistics. The period of the study is from the year 1995-96 to 2017-18.

\section{Statistical tools}

Statistical tools like compound growth rate and Cuddy-Della Valle Index were used to analyze growth rates and instability in area, production and productivity of major oilseeds in India respectively.

\section{Compound growth rate}

It is calculated as;

C.G.R. $(\%)=($ Antilog $b-1){ }^{*} 100$

where, $b=$ regression coefficient

\section{Cuddy Della Valle Instability index}

(Cuddy and Della Valle 1978) is a modification of coefficient of variation to accommodate trend present in the data, which is commonly present in economic time series data. This method is superior over the scale dependent measures such as standard deviation. The Cuddy Della Valle index (CDVI) is calculated as follows:

Cuddy - Della Valle Index $(\%)=C . V \cdot * \sqrt{\left(1-R^{2}\right)}$

where, $C . V .=$ Coefficient of Variation

$\mathrm{R}^{2}=$ Coefficient of multiple determination

The ranges of CDVI (Sihmar, 2014) are given as follows:

Low instability $=$ between 0 and 15 
Medium instability $=$ greater than 15 and lower than 30

High instability $=$ greater than 30

\section{RESULTS AND DISCUSSION}

Table 1 depicted the extent of growth and instability in area, production and productivity of soybean in major states like Madhya Pradesh and Maharashtra during the year 1995-96 to 2017-18. The compound growth rate of soybean in area under Madhya Pradesh showed highly significant positive rate with 1.72 per cent of growth per annum. In the same way production of soybean in the state also showed highly significant growth rate of 2.52 per cent per annum. But the productivity of soybean in the state didn't showed any significant results although increased with positive growth rate of 0.79 per cent per annum.

The compound growth rate of area under soybean in Maharashtra was found to be increased at highly significant rate with 8.72 per cent of growth per annum. In the same way production of soybean in the state also showed highly significant growth rate of 7.44 per cent per annum. But the productivity of soybean in the state surprisingly showed insignificant negative results with growth rate of -1.18 per cent per annum.
The instability index was calculated by Cuddy-Della Valle Index for area, production and productivity of soybean in states like Madhya Pradesh and Maharashtra. Results showed that in Madhya Pradesh variation in area under soybean registered low instability $(12.83 \%)$ whereas production and productivity of soybean in the state registered variation with high instability of 37.98 and 31.61 per cent respectively.

In Maharashtra CDVI results depicted that variations in area under soybean was having low instability with 10.41 per cent as of in Madhya Pradesh but production and productivity of soybean in the state during the study period showed variations of medium instability with 26.68 and 19.53 per cent respectively which was lesser than the variations found in Madhya Pradesh.

Growth and instability in area, production and productivity of rapeseed \& mustard in major states like Haryana, Rajasthan, Madhya Pradesh and Uttar Pradesh during the year 1995-96 to 2017-18 were analysed and presented in Table 2. The area of rapeseed \& mustard in Haryana during the study period showed negative growth rate with -0.21 per cent per annum. But the production and productivity of the crop in the state registered highly significant positive growth rate with 1.99 and 2.21 per cent per annum.

Table 1: Growth \& instability of area, production and productivity of soybean in major states of India during $1995-96$ to $2017-18$

\begin{tabular}{llllllll}
\hline \multirow{2}{*}{ Sl. No. } & \multirow{2}{*}{ States } & \multicolumn{4}{c}{ CGR (\%) } & \multicolumn{2}{c}{ CDVI (\%) } \\
\cline { 3 - 8 } & Area & Production & Productivity & Area & Production & Productivity \\
\hline 1 & Madhya Pradesh & $1.72^{* *}$ & $2.52^{* *}$ & 0.79 & 12.83 & 37.98 & 31.61 \\
2 & Maharashtra & $8.72^{* *}$ & $7.44^{* *}$ & -1.18 & 10.41 & 26.68 & 19.53 \\
\hline
\end{tabular}

Source: Department of Agriculture, Cooperation and Farmers Welfare, Ministry of Agriculture and Farmers Welfare, Government of India, New Delhi.

**significance at 1 per cent level (highly significant) * significance at 5 per cent level (significant).

Table 2: Growth \& instability of area, production and productivity of rapeseed \& mustard in major states of India during 1995-96 to 2017-18

\begin{tabular}{llllllll}
\hline \multirow{2}{*}{ S1. No. } & \multirow{2}{*}{ States } & \multicolumn{4}{c}{ CGR (\%) } & \multicolumn{3}{c}{ CDVI (\%) } \\
\cline { 2 - 7 } & Area & Production & Productivity & Area & Production & Productivity \\
\hline 1 & Haryana & -0.21 & $1.99^{* *}$ & $2.21^{* *}$ & 13.02 & 17.35 & 15.38 \\
2 & Rajasthan & $0.28^{*}$ & $2.79^{* *}$ & $2.50^{* *}$ & 23.08 & 23.90 & 10.52 \\
3 & Madhya Pradesh & 1.05 & $3.18^{* *}$ & $2.11^{* *}$ & 16.29 & 21.05 & 11.09 \\
4 & Uttar Pradesh & $-2.93^{* *}$ & $-1.47^{* *}$ & $1.50^{* *}$ & 10.53 & 16.48 & 11.97 \\
\hline
\end{tabular}

Source: Department of Agriculture, Cooperation and Farmers Welfare, Ministry of Agriculture and Farmers Welfare, Government of India, New Delhi.

**ignificance at 1 per cent level (highly significant) * significance at 5 per cent level (significant). 
In Rajasthan all three variables such as area, production and productivity depicted highly significant positive growth rate with $0.28,2.79$ and 5.50 per cent per annum respectively. The increase in output growth is mainly driven by increase in yield which could be attributed to improved technology, adoption of good agronomic practices and input use. The results are in conformity with the results of Kumar et al. (2018). In Madhya Pradesh only, area under the crop showed insignificant positive growth rate with 1.05 per cent per annum but the production and productivity of the crop in the state during the study period registered highly significant positive growth rate of 3.18 and 2.11 per cent per annum respectively. Area and production of rapeseed \& mustard in Uttar Pradesh during the study period found to be declining with highly significant growth rate of -2.93 and -1.47 per cent per annum but the productivity of the crop in the state showed positive growth rate of 1.50 per cent per annum which was highly significant.

Instability index results showed that variation in area of rapeseed and mustard in Haryana state was low with 13.02 per cent but the production and productivity of the crop in the state during the study period showed medium instability with 17.35 and 15.38 per cent respectively. Area and production of rapeseed and mustard in Rajasthan showed medium instability with 23.08 and 23.90 per cent. But the productivity of the crop was found to show low instability with 10.52 per cent. The low and moderate instability indicate that the development of new technology over years and favourable policy environment have played major role in stabilizing area, production and yield of rapeseed mustard in
Rajasthan state as found by results of Kumar et al. (2018).

Area and productivity instability of rapeseed and mustard in Uttar Pradesh was found to be low with 10.53 and 11.97 per cent respectively but the production instability was moderate with 16.48 per cent.

Table 3 indicated growth rate and instability index for area, production and productivity of groundnut in major states across India during the study period. It was found that area and production of groundnut in Andra Pradesh declined with highly significant growth rates of 4.02 and 4.26 per cent per annum respectively during the study period. But the productivity of the same didn't show any significant results. As per as instability is concerned the variation in area of the crop was found to be low with 12.83 per cent but production and productivity of the crop in Andra Pradesh showed high instability with 37.98 and 31.61 per cent respectively.

In Karnataka, there was highly significant negative growth rate in area and production of groundnut with -3.32 and 3.72 per cent per annum respectively. But productivity showed insignificant negative growth rate. Area instability was found to be low with 10.41 per cent but instability of production and productivity was moderate with 26.68 and 19.53 per cent respectively. The decrease in supply of groundnut and high instability is attributed to decrease in area and productivity because the crop area has been switched to cash crops like sugarcane, cotton etc. The droughts and insufficient monsoon rains have also affected the production and productivity of oilseeds in Karnataka as results found in Behera \& Basavaraja, (2017).

Table 3: Growth \& instability of area, production and productivity of groundnut in major states of India during 1995-96 to 2017-18

\begin{tabular}{llllllll}
\hline \multirow{2}{*}{ S1. No. } & \multirow{2}{*}{ States } & \multicolumn{3}{c}{ CGR (\%) } & \multicolumn{3}{c}{ CDVI (\%) } \\
\cline { 3 - 7 } & & Area & Production & Productivity & Area & Production & Productivity \\
\hline 1 & Andra Pradesh & $-4.02^{* *}$ & $-4.26^{* *}$ & -0.25 & 12.83 & 37.98 & 31.61 \\
2 & Karnataka & $-3.32^{* *}$ & $-3.72^{* *}$ & -0.42 & 10.41 & 26.68 & 19.53 \\
3 & Gujarat & $-1.02^{* *}$ & $3.43^{*}$ & $4.50^{* *}$ & 8.67 & 43.33 & 39.28 \\
4 & Maharashtra & $-2.98^{* *}$ & $-2.57^{* *}$ & 0.21 & 9.61 & 15.38 & 8.96 \\
5 & Rajasthan & $4.13^{* *}$ & $10.14^{* *}$ & $4.35^{* *}$ & 18.42 & 50.87 & 25.73 \\
6 & Tamil Nadu & $-5.29^{* *}$ & $-1.46^{*}$ & $4.05^{* *}$ & 10.64 & 24.64 & 16.26 \\
\hline
\end{tabular}

Source: Department of Agriculture, Cooperation and Farmers Welfare, Ministry of Agriculture and Farmers Welfare, Government of India, New Delhi.

** significance at 1 per cent level (highly significant) * significance at 5 per cent level (significant). 
Area of groundnut in Gujarat registered declining but highly significant growth rate of -1.02 per cent per annum during the study period. Production and productivity of groundnut showed highly significant positive growth rate with 3.43 and 4.50 per cent per annum, respectively in the state. CDVI results showed that instability of production and productivity of groundnut in Gujarat was high with 43.33 and 39.28 per cent, respectively, but the area instability was found to be low with 8.67 per cent. The study by Sanjay et al. (2018), therefore, recommended the development and spread of innovations at an affordable price to farmers. Effective disease and pest control measures should be developed to check the perennial pest infestation of crop in the state.

Only a few states like Haryana, Madhya Pradesh, Maharashtra, Rajasthan and West Bengal have increased their oilseeds production both through area expansion and productivity improvement. State like Gujarat has increased oilseeds production mainly due to productivity improvement as found in results of Narayan, (2016).

Area and production of groundnut in Maharashtra was found to be declined at highly significant rate with -2.98 and -2.57 per cent per annum respectively. But the productivity showed insignificant positive growth rate. According to CDVI results low instability was noticed in area and productivity where as moderate instability found in production of groundnut in the state. Low instability may be due to technological and other government interventions according to results of Reddy and Immanuelraj, (2017).

Area, production and productivity groundnut in Rajasthan during the study period was found to be increased at highly significant growth rate of 4.13, 10.14 and 4.35 per cent per annum respectively. Variations in area and productivity were found to be moderate whereas high instability was noticed in production. Highly significant and significant negative growth rate were found in area and production of groundnut in Tamil Nadu with -5.29 and -1.46 per cent per annum respectively but productivity was increased at highly significant growth rate of 4.05 per cent per annum. Area instability was low with 10.64 per cent whereas production and productivity showed medium instability with 24.64 and 16.26 per cent respectively. Hence, the study by Pallab et al. (2015) highly recommends the use and adoption of site-specific scientific package of practices of the crop to avoid the prevailed instability.

\section{CONCLUSION}

Oilseeds are significant following only to food grains in terms of area; production and value and play a vital role in food and nutritional security of the country. India is the largest producer of oilseeds in the world and oilseed sector occupies an important position in the agricultural economy of the country. Soybean, rapeseed \& mustard and groundnut are the major oilseed crops sharing more than 80 per cent of production in India. Productivity level of Rabi season oilseeds (Rapeseed \& Mustard) is higher than Kharif season oilseeds (Soybean \& Groundnut) due to lower pest problem and assured irrigation availability. It can be noted from the study that soybean has performed well in terms of area and production in both the major producing states but the instability was found to be moderate to high in production and yield which indicates irregular rainfall and drought conditions. Production and yield of rapeseed \& mustard in all major states were found to be performed well and also the instability in these states was low to medium. Only in Uttar Pradesh, the area and production were found to be performed negatively because of the shifting of the crop to barley and wheat. Area and production of groundnut in all the major states were found to be performed negatively because of the shifting to crops like bajra, paddy and cotton. Fluctuations in production and yield were also high which may be due to abiotic factors like rainfall, temperature and humidity etc.

Hence some of the recommendations based on the present study are:

- there is a need to provide proper irrigation facilities along with timely alerts on weather forecast

- providing proper incentives and subsidies to the farmers for growing essential major oilseeds.

- adoption of site-specific scientific package of practices of the crop to avoid the prevailed instability. 
- development and spread of innovations at an affordable price to farmers. Effective disease and pest control measures should be developed to check the perennial pest infestation of crops in the state.

\section{REFERENCES}

Behera, J. and Basavaraja H. 2017. Demand and supply estimation for oilseeds in Karnataka. J. Farm Sci., 30(1): 79-81.

Department of Agriculture, Cooperation and Farmers Welfare, Ministry of Agriculture and Farmers Welfare, Government of India, New Delhi, https://eands.dacnet. nic.in/

Food and Agriculture Organization of the United Nations, http://www.fao.org/faostat/en/\#data

Kumar, D., Sharma, M., Sharma, R. and Awais, M. 2018. A Study of Growth Performance and Economics of Rapeseed and Mustard Cultivation in Rajasthan, India. International Journal of Pure E Applied Bioscience, 6(6): 804-809.
Kumari, S. 2012. Growth and Instability of Major Oilseed Production in India. ABM Thesis, Department of Agricultural Economics, Institute of Agricultural Sciences, Banaras Hindu University, Varanasi - 221005. (INDIA)

Narayan, P. 2016. Recent Demand-Supply and Growth of Oilseeds and Edible Oil in India: An Analytical Approach. International Journal of Advanced Engineering Research and Science, 4(1): 32-46.

Pallab, D., Singh, R., Feroze, S.M. and Sarkar, A. 2015. Study on Growth and Instability of Sesame in North-Eastern Hill Region of India. Economic Affairs, 60(2): 193-196.

Reddy, V.K. and Immanuelraj, K.T. 2017. Area, Production, Yield Trends and Pattern of Oilseeds Growth in India. Economic Affairs, 62(2): 327-334.

Sanjay, Seidu, M. and Kundu, K.K. 2018. Growth and instability in cotton cultivation in Northern India. Economic Affairs, 63(2): 433-440.

Sihmar, R. 2014. Growth and Instability in Agricultural Production in Haryana: A District level Analysis. International Journal of Scientific and Research Publications, 4(7): 1-12. 